\title{
Effects of the 2009 USPSTF Depression Screening Recommendation on Diagnosing and Treating Mental Health Conditions in Older Adults: A Difference-in-Differences Analysis
}

\author{
Taeho Greg Rhee, PhD, MSW; Benjamin D. Capistrant, ScD;
}

Jon C. Schommer, PhD; Ronald S. Hadsall, PhD; and Donald L. Uden, PharmD

\begin{abstract}
BACKGROUND: Depression is a common mental condition in U.S. older adults. To improve rates of underdiagnosis and undertreatment for depression and other mental health conditions in primary care settings, the U.S. Preventive Services Task Force (USPSTF) updates and disseminates its depression screening guideline regularly.

OBJECTIVE: To examine the effects of the 2009 USPSTF depression screening recommendation on the 3 following outcomes: diagnoses of mental health conditions, antidepressant prescriptions (overall and potentially inappropriate), and provision of nonpharmacological psychiatric services in officebased outpatient primary care visits made by adults aged 65 or older.

METHODS: Data from the 2006-2012 National Ambulatory Medical Care Survey (NAMCS), a nationally representative sample of office-based outpatient primary care visits among older adults ( $n=15,596$ unweighted), were used. NAMCS represents physician practicing patterns of ambulatory medical care services utilization at the national level. Using a series of multivariate difference-in-differences analyses, we estimated effects of the USPSTF depression screening recommendation on the previously mentioned outcomes by comparing pre- (2006-2009) and post- (2010-2012) periods to describe primary care physician practice patterns.
\end{abstract}

RESULTS: Differences in any mental health diagnosis by the depression screening status were $-34.7 \%$ in the pre- 2009 period and $-20.2 \%$ in the post2009 period, resulting in a differential effect of $-14.4 \%(95 \% \mathrm{Cl}=-28.2,-0.6$; $P=0.040$ ). No differential effect was found in other outcomes.

CONCLUSIONS: While there are mixed findings about efficacy and effectiveness of depression screening in the existing literature, more population-based observational research is needed to strengthen and support current USPSTF depression screening recommendation statements in the United States.

J Manag Care Spec Pharm. 2018;24(8):769-76

Copyright $\odot 2018$, Academy of Managed Care Pharmacy. All rights reserved.

\section{What is already known about this subject}

Older adults are at risk of having depression and other psychiatric disorders, yet they may be often undiagnosed and untreated. U.S. Preventive Services Task Force (USPSTF) regularly updates and disseminates depression screening guidelines for primary care health care providers.

\section{What this study adds}

This study investigated USPSTF depression screening recommendations for diagnoses of mental health conditions, antidepressant prescriptions, and provision of nonpharmacological psychiatric services among older adults in outpatient care.

Study findings show that at the national level the effects of guideline recommendations are minimal.

A ging-related depression is the leading cause of disability and the major contributor for disease burden, and depression and other related mood disorders are often underdiagnosed and undertreated among adults aged 65 and over (hereafter referred to as older adults). ${ }^{1,2}$ While adults with depression are not likely to make psychiatry-related visits, they still seek care in primary care or other specialty visits, making "these visits particularly important opportunities to detect and initiate treatment of depression." ${ }^{3}$ In light of providing care for depression in primary care and other specialty visits, screening for depression has become a "prominent component of the 'detect-treat-improve' paradigm for undetected depression" since the mid-1990s. ${ }^{3}$

In 2002, the U.S. Preventive Services Task Force (USPSTF) recommended depression screening for all eligible adults. ${ }^{4}$ Subsequently, the 2009 USPSTF practice recommendation stated that depression screening should be provided in eligible adults to "ensure accurate diagnosis, effective treatment, and appropriate follow-up" related to depression and other mental health conditions. 5,6 The 2009 USPSTF guideline distinguished 2 different recommendations: a grade $\mathrm{B}$ recommendation is given when staff-assisted depression care supports are in place, and a grade C recommendation is given when staff-assisted depression care supports are not present in primary care settings. ${ }^{6}$ Unlike the grade $\mathrm{B}$ recommendation, the grade $\mathrm{C}$ recommendation indicates that the USPSTF makes no recommendation for or against routine depression screening service, and the service may be provided based on professional judgment and/or patient preferences. ${ }^{6}$

While clinical and policy efforts have been made in the past decades, depression screening is still a controversial topic in the existing literature. Advocates of depression screening 
suggest that it should be actively utilized since both detection and treatment rates of depression are relatively low given the fact that prevalence rates of depression and other mood disorders are high among older adults in ambulatory care settings. ${ }^{7,8}$ However, critics argue that depression screening may not be a cost-effective approach due to its high false-positive rates. ${ }^{7}$

In the existing literature, some studies have assessed the policy effect of recent USPSTF guidelines (e.g., mammography use and pediatric urinalysis), ${ }^{9,10}$ No study has yet assessed the effect of the 2009 depression screening recommendation, including among older adults aged 65 and over. Gaps remain in our understanding of whether the 2009 depression screening recommendation had effects on the following outcomes: diagnoses of depression and other psychiatric disorders, overall and potentially inappropriate antidepressant prescriptions, and provision of nonpharmacological psychiatric services among older adults.

In this study, we focused on older adults only for 2 reasons. First, they have greater rates of underdiagnosis and undertreatment for depression and other psychiatric disorders, while they have a higher depression rate than any other age group. ${ }^{11}$ Second, our conceptualization of potentially inappropriate antidepressant use was based on the Beers Criteria, which strictly apply to the older adult population only. We hypothesized that depression screening may help increase diagnosis rates of depression or other psychiatric disorders because the depression screening guideline is a tool to detect depression or other psychiatric disorders in a timely manner. Additionally, a recent study from Rhee et al. (2017) suggests that depression screening was associated with a reduced rate of potentially inappropriate antidepressant prescriptions. ${ }^{11}$ Based on this, we hypothesized that the depression screening would be associated with a decreased rate of potentially inappropriate antidepressant prescriptions. To address these knowledge gaps, we examined the policy effects of the 2009 USPSTF depression screening recommendation on the previously mentioned outcomes between pre- (2006-2008) and post- (2010-2012) periods in office-based outpatient primary care visits made by older adults.

\section{Methods}

\section{Data Source and Study Sample}

Data used in this study originated from the 2006-2012 National Ambulatory Medical Care Survey (NAMCS), which is administrated by National Center for Health Statistics of the Centers for Disease Control and Prevention. ${ }^{12}$ The NAMCS is an annual, cross-sectional survey of visits to office-based physiciansin outpatientsettingsand providesreliable information about the provision and/or use of ambulatory medical care services in the United States. ${ }^{12}$ Using a complex sampling design, selected physicians took the survey, resulting in a systematic random sample of office-based outpatient visits.
Further, NAMCS utilizes an automated patient record form to collect information about the patient's demographic and clinical characteristics (e.g., clinical diagnosis and medications prescribed) in a sampled visit. The analytic sample used in this study included office-based outpatient primary care visits made by older adults aged 65 and over and had completed data for all covariates ( $n=15,596$ unweighted). As this study used publicly available data, the research procedure for this study was exempted by the Institutional Review Board at University of Minnesota, Twin Cities. Further details of the survey, including descriptions, questionnaires, sampling methodology, and datasets, are publicly available on the NAMCS website. ${ }^{13}$

\section{Measures}

Dependent Variables. The 3 main outcomes of interest were diagnosis of mental health conditions, antidepressant prescribing (overall and potentially inappropriate), and provision of nonpharmacological psychiatric services. First, we included the diagnosis of mental health conditions. The NAMCS collects up to 3 clinical diagnoses using International Classification of Diseases, Ninth Revision, Clinical Modification (ICD-9-CM) diagnostic codes. Based on Olfson et al.'s work (2014), ${ }^{14}$ we constructed binary variables (yes or no) for diagnosis of mental health conditions as follow: mood disorders (ICD-9-CM diagnostic codes 293.83, 296, 298.0, 300.4, 301.1, 311, or 313.1), anxiety disorders (ICD-9-CM diagnostic codes 293.84, 300.0, 300.2, 300.3, 308.3, 309.21, or 309.81), psychoses/ developmental disorders (ICD-9-CM diagnostic codes 290.0295.9, 297.0-298.0, 298.3-299.9, 310.0-310.9, or 317-319), and other mental disorders (ICD-9-CM diagnostic codes 290-319, not included in aforementioned codes). We also constructed a comorbid mental disorder diagnosis variable indicating the presence of 2 or more diagnostic groups (mood, anxiety, psychoses/developmental, or other).

Antidepressant prescription was another outcome measure. The NAMCS collected data on up to 8 medications in 2006-2011 and up to 10 medications in 2012. Using the 2015 American Hospital Formulary Service (AHFS) Compendium, Wolters Kluwer's Drug Facts and Comparisons, and previous studies, we identified prescribed antidepressant medications using generic names (Table 1)..$^{8,11,14-18}$ We constructed a binary variable (yes or no) for overall antidepressant prescriptions. For potentially inappropriate antidepressant prescriptions, we constructed a binary variable (yes or no) using the 2012/2015 Beers Criteria (Table 1 and Table 2).19,20

Third, we included nonpharmacological psychiatric service use as an outcome measure. The NAMCS asks 2 questions to assess whether psychotherapy and mental health counseling other than psychotherapy were provided (yes or no). ${ }^{21}$ Due to the limited sample size, a binary variable (yes or no) was created aggregating these 2 questions. 
Effects of the 2009 USPSTF Depression Screening Recommendation on Diagnosing and

Treating Mental Health Conditions in Older Adults: A Difference-in-Differences Analysis

TABLE 2 2012/2015 Beers Criteria for Potentially Inappropriate Antidepressant Use in Older Adults Due to Drug-Disease or Drug-Syndrome Interactions That May Exacerbate the Disease or Syndrome ${ }^{19,20}$

\begin{tabular}{|c|c|c|c|c|c|}
\hline $\begin{array}{l}\text { Disease or Syndrome } \\
\text { (ICD-9-CM Code) }\end{array}$ & Antidepressant ${ }^{a}$ & Rationale & Recommendation & $\begin{array}{l}\text { Quality of } \\
\text { Evidence }\end{array}$ & $\begin{array}{c}\text { Strength of } \\
\text { Recommendation }\end{array}$ \\
\hline \multicolumn{6}{|l|}{ Cardiovascular } \\
\hline $\begin{array}{l}\text { Syncope } \\
(780.2,992.1)\end{array}$ & Tertiary TCAs & $\begin{array}{l}\text { Increase risk of orthostatic } \\
\text { hypotension or bradycardia }\end{array}$ & Avoid & Moderate & Strong \\
\hline \multicolumn{6}{|l|}{ Central nervous system } \\
\hline $\begin{array}{l}\text { Chronic seizures or epilepsy } \\
(345,780.33)\end{array}$ & $\begin{array}{l}\text { Bupropion, } \\
\text { maprotiline }\end{array}$ & $\begin{array}{l}\text { Lowers seizure threshold; may } \\
\text { be acceptable in patients with } \\
\text { well-controlled seizures in whom } \\
\text { alternative agents have not been } \\
\text { effective }\end{array}$ & Avoid & Moderate & Strong \\
\hline $\begin{array}{l}\text { Delirium } \\
(290.11,290.3,290.41,291.0, \\
292.81,293.0,293.1)\end{array}$ & $\begin{array}{c}\text { TCAs, } \\
\text { anticholinergics }\end{array}$ & $\begin{array}{l}\text { Induce or worsen delirium in } \\
\text { older adults; if discontinuing } \\
\text { drugs used chronically, taper to } \\
\text { avoid withdrawal symptoms }\end{array}$ & Avoid & Moderate & Strong \\
\hline $\begin{array}{l}\text { Dementia and cognitive impairment } \\
(290,291.2,292.82,294.10,294.11, \\
294.20,294.21,331.0,331.19, \\
331.82,331.83)\end{array}$ & Anticholinergics & $\begin{array}{l}\text { Avoid because of adverse CNS } \\
\text { effects }\end{array}$ & Avoid & High & Strong \\
\hline $\begin{array}{l}\text { History of falls or fractures } \\
\text { (E880-E888) }\end{array}$ & TCAs, SSRIs & $\begin{array}{l}\text { Ability to produce ataxia, } \\
\text { impaired psychomotor function, } \\
\text { syncope, and additional falls }\end{array}$ & $\begin{array}{c}\text { Avoid unless safer } \\
\text { alternatives are not } \\
\text { available }\end{array}$ & High & Strong \\
\hline \multicolumn{6}{|l|}{ Gastrointestinal } \\
\hline $\begin{array}{l}\text { Chronic constipation } \\
(564)\end{array}$ & $\begin{array}{l}\text { Tertiary TCAs, } \\
\text { anticholinergics }\end{array}$ & Can worsen constipation & $\begin{array}{l}\text { Avoid unless no } \\
\text { other alternatives }\end{array}$ & Moderate to low & Weak \\
\hline $\begin{array}{l}\text { Lower urinary tract symptoms, } \\
\text { benign prostatic hyperplasia } \\
(600)\end{array}$ & Anticholinergics & $\begin{array}{l}\text { May decrease urinary flow and } \\
\text { cause urinary retention }\end{array}$ & Avoid in men & Moderate & $\begin{array}{l}\text { Inhaled agents: } \\
\text { strong; others: weak }\end{array}$ \\
\hline
\end{tabular}

aRefer to Table 1 for full description.

CNS = central nervous system; ICD-9-CM = International Classification of Diseases, Ninth Revision, Clinical Modification; TCA=tricyclic antidepressant; SSRI = selective serotonin reuptake inhibitor.

time periods. For demographic characteristics, age, race/ ethnicity, and region did not differ significantly between time periods. Gender and the source of payment did differ significantly, such that more visits were made by male older adults $(P=0.001)$ and covered by Medicare $(P<0.001)$ in the post-2009 time period. Clinical characteristics, reason for visit, type of medical practice, and MSA status did not differ across time periods. Between 2006 and 2008, 74.4\% of patients had 3 or more visits in the past 12 months, and this rate was significantly higher than that of the post-2009 period (68.9\%; $P<0.001)$. The distribution of time spent with a doctor differed significantly across the time periods $(P<0.001)$. For example, $34.1 \%$ of visits had 21 or more minutes spent with a doctor in the post-2009 period, which is significantly higher than that of the pre-2009 period (23.3\%). We also observed that the number of multiple chronic conditions and the number of medications prescribed varied by the time period ( $P=0.006$ and $P=0.001$, respectively). For instance, $71.3 \%$ of older adults had 2 or more chronic conditions in the post-2009 period, which was higher than that of the pre-2009 period (67.1\%). Similarly, $67.7 \%$ of older adults who had visits had 3 or more concomitant medications prescribed in the post-2009 period, which was higher than that of the pre-2009 period (63.1\%).

\section{Difference-in-Differences}

Table 4 presents the adjusted prevalence of selected outcomes in office-based outpatient primary care visits made by older adults by depression screening status and the time period. Overall, the prevalence of diagnosis with any mental disorder significantly decreased from $40.2 \%$ in pre-2009 to $26.6 \%$ in post-2009 in visits with depression screening. On the other hand, the prevalence of diagnosis with any mental disorders increased from $5.5 \%$ in pre-2009 to $6.4 \%$ in post-2009 in visits without depression screening. Differences by the depression screening status were $-34.7 \%$ in the pre-2009 period and $-20.2 \%$ in the post2009 period, resulting in a differential effect of $-14.4 \%(95 \%$ confidence interval $[\mathrm{CI}]=-28.2,-0.6 ; P=0.040$ ). In subgroup analyses, no differential effect was found in mood disorders, anxiety disorders, or psychosis/developmental disorders. In the case of other disorders that are not mood disorders, anxiety disorders, or psychosis/developmental disorders, the differential magnitude was large $(-8.5 \%)$, even though it was not statistically significant $(95 \% \mathrm{CI}=-17.0,0.1 ; P=0.053)$. No differential effect due to the 2009 USPSTF depression screening recommendation was found in the cases of antidepressant prescription patterns $(P=0.680)$ and the utilization of psychiatric services $(P=0.679)$. 
Effects of the 2009 USPSTF Depression Screening Recommendation on Diagnosing and

Treating Mental Health Conditions in Older Adults: A Difference-in-Differences Analysis

TABLE 3 Selected Baseline Characteristics (Weighted Percent) of Older Adults in Office-Based Outpatient Primary Care Settings by Time Periods, 2006-2012 NAMCS

\begin{tabular}{|c|c|c|c|c|c|c|c|c|c|}
\hline & $\begin{array}{c}\text { Pre-2009 } \\
(2006- \\
2008) \\
\end{array}$ & $\begin{array}{c}\text { Post-2009 } \\
(2010- \\
2012) \\
\end{array}$ & Total & $P$ Value & & $\begin{array}{c}\text { Pre-2009 } \\
(2006- \\
2008) \\
\end{array}$ & \begin{tabular}{|c|} 
Post-2009 \\
$(2010-$ \\
$2012)$ \\
\end{tabular} & Total & $P$ Value \\
\hline \multicolumn{5}{|l|}{ Depression screening } & \multicolumn{5}{|l|}{ Reason for visit } \\
\hline No & 98.1 & 98.1 & 98.1 & 0.963 & Acute problem & 32.5 & 31.3 & 31.9 & 0.265 \\
\hline Yes & 1.9 & 1.9 & 1.9 & & Routine chronic problem & 50.9 & 49.3 & 50.1 & \\
\hline \multicolumn{5}{|l|}{ Mental disorder diagnosis } & Preventive care & 14.3 & 16.6 & 15.4 & \\
\hline No & 93.7 & 93.1 & 93.4 & 0.330 & Pre- or postsurgery & 2.3 & 2.9 & 2.6 & \\
\hline Yes & 6.3 & 6.9 & 6.6 & & \multicolumn{5}{|l|}{ Repeat of visits } \\
\hline \multicolumn{5}{|l|}{ Antidepressant prescribed } & 0 visits & 2.6 & 4.5 & 3.3 & $<0.001$ \\
\hline No & 88.1 & 87.2 & 87.7 & 0.470 & $1-2$ visits & 23.0 & 26.6 & 24.4 & \\
\hline Yes, appropriate & 10.4 & 11.4 & 10.9 & & 3-5 visits & 39.3 & 39.3 & 39.3 & \\
\hline Yes, potentially inappropriate & 1.5 & 1.4 & 1.5 & & $6+$ visits & 35.1 & 29.6 & 33.0 & \\
\hline \multicolumn{5}{|c|}{ Psychotherapy or other mental health counseling provided } & \multicolumn{5}{|l|}{ Type of medical practice } \\
\hline No & 99.4 & 99.3 & 99.3 & 0.669 & Solo & 89.0 & 89.5 & 89.3 & 0.832 \\
\hline Yes & 0.6 & 0.7 & 0.7 & & Otherc & 11.0 & 10.5 & 10.7 & \\
\hline \multicolumn{5}{|l|}{ Age, years } & \multicolumn{5}{|l|}{ MSA status } \\
\hline$\frac{65-74}{75-84}$ & $\frac{49.7}{36.8}$ & $\frac{50.5}{350}$ & $\frac{50.1}{350}$ & 0.227 & MSA & 80.6 & 79.7 & 80.1 & 0.780 \\
\hline$\frac{15-84}{85+}$ & $\frac{36.8}{13.6}$ & $\frac{35.0}{14.5}$ & $\begin{array}{l}35.9 \\
14.0\end{array}$ & & Non-MSA & 19.4 & 20.3 & 19.9 & \\
\hline \multicolumn{5}{|l|}{ Gender } & \multicolumn{5}{|l|}{ Time spent with doctor } \\
\hline Female & 59.9 & 56.7 & 58.3 & 0.012 & $<15$ min. & 14.8 & 14.0 & 14.4 & $<0.001$ \\
\hline Male & 40.1 & 43.3 & 41.7 & & 15-20 min. & 61.8 & 52.0 & 56.9 & \\
\hline \multicolumn{5}{|l|}{ Race/ethnicity } & 21-30 min. & 16.2 & 22.0 & 19.1 & \\
\hline Non-Hispanic white & 77.9 & 78.2 & 78.0 & 0.935 & $>30 \mathrm{~min}$ & 7.1 & 12.1 & 9.6 & \\
\hline Non-Hispanic black & 9.4 & 8.6 & 9.0 & & \multicolumn{5}{|l|}{ Multiple chronic conditions } \\
\hline Hispanic & 8.3 & 8.4 & 8.3 & & None & 11.1 & 8.8 & 10.0 & 0.008 \\
\hline Other $^{\mathrm{a}}$ & 4.5 & 4.9 & 4.7 & & 1 & 21.8 & 19.9 & 20.9 & \\
\hline \multicolumn{5}{|l|}{ Region } & $2-3$ & 47.4 & 47.2 & 47.3 & \\
\hline Northeast & 17.0 & 18.6 & 17.8 & 0.096 & $4+$ & 19.7 & 24.1 & 21.9 & \\
\hline Midwest & 19.7 & 21.7 & 20.7 & & \multicolumn{5}{|l|}{ Number of medications } \\
\hline South & 43.4 & 35.7 & 39.6 & & 0 & 11.8 & 11.1 & 11.5 & 0.001 \\
\hline West & 19.8 & 24.0 & 21.9 & & $1-2$ & 25.1 & 21.2 & 23.2 & \\
\hline \multicolumn{5}{|l|}{ Source of payment } & $3-5$ & 29.4 & 25.8 & 27.6 & \\
\hline Private & 17.2 & 14.7 & 15.9 & $<0.001$ & $6+$ & 33.7 & 41.9 & 37.7 & \\
\hline Medicare & 75.9 & 82.4 & 79.1 & & \multicolumn{5}{|l|}{ Sample size } \\
\hline Medicaid & 4.9 & 1.6 & 3.3 & & Unweighted sample & 6,283 & 9,313 & 15,596 & \\
\hline Otherb & 2.1 & 1.3 & 1.7 & & Weighted visits & $47,087,308$ & $46,502,737$ & $93,590,045$ & \\
\hline \multicolumn{10}{|c|}{$\begin{array}{l}\text { ancludes Asians, American Indian/Alaska Natives, Native Hawaiian or Other Pacific Islan } \\
\text { 'Includes worker's compensation, self-pay, no charge, and others. } \\
\text { 'Includes federally qualified health center, non-federal government clinic, family planning cl } \\
\text { faculty practice plan. } \\
\text { MSA = metropolitan statistical area; NAMCS = National Ambulatory Medical Care Survey. }\end{array}$} \\
\hline
\end{tabular}

\section{Discussion}

This is the first population-based observational study to examine the effects of the 2009 USPSTF depression screening recommendation in office-based outpatient visits made by older adults. Overall, the diagnosis of any mental disorder had a differential effect $(-14.4 \%$; $95 \% \mathrm{CI}=-28.2,-0.6)$. While there is no clear explanation from this population-based observational data, there are 2 plausible reasons for this phenomenon. One would be that primary care physicians have different medical practice patterns compared to psychiatrists, who are specialized in mental health diagnoses and psychopharmacological interventions. The other possibility may be patient perceptions. Older patients, unlike their younger counterparts, may still be sensitive to stigma related to mental health issues. Besides these, there might be unobserved confounders that can explain this finding. Future research, however, is needed to better understand such medical practice patterns and how they may affect mental health outcomes of older patients. 
Effects of the 2009 USPSTF Depression Screening Recommendation on Diagnosing and

Treating Mental Health Conditions in Older Adults: A Difference-in-Differences Analysis

TABLE 4 Adjusted Proportion of Selected Outcomes Among Older Adults in Office-Based Outpatient Primary Care Settings by Depression Screening, NAMCS 2006-2012

\begin{tabular}{|c|c|c|c|c|c|c|c|c|c|}
\hline & \multicolumn{2}{|c|}{$\begin{array}{l}\text { With Depression } \\
\text { Screening, \% }\end{array}$} & \multicolumn{2}{|c|}{$\begin{array}{l}\text { Without Depression } \\
\text { Screening, \% }\end{array}$} & \multicolumn{2}{|c|}{ Difference, \% } & \multicolumn{3}{|c|}{ Difference-in-Differences, \% } \\
\hline & $\begin{array}{c}\text { Pre-2009 } \\
(2006- \\
2008)\end{array}$ & $\begin{array}{c}\text { Post-2009 } \\
(2010- \\
2012)\end{array}$ & $\begin{array}{c}\text { Pre-2009 } \\
(2006- \\
2008)\end{array}$ & $\begin{array}{c}\text { Post-2009 } \\
(2010- \\
2012)\end{array}$ & $\begin{array}{c}\text { Pre-2009 } \\
(2006- \\
2008)\end{array}$ & $\begin{array}{c}\text { Post-2009 } \\
(2010- \\
2012)\end{array}$ & Coefficient & $95 \%$ CI & $P$ Value \\
\hline \multicolumn{10}{|l|}{ Mental disorder diagnosis } \\
\hline Any mental disorder & 40.2 & 26.6 & 5.5 & 6.4 & -34.7 & -20.2 & -14.4 & $-28.2-0.6$ & 0.040 \\
\hline Mood disorder & 26.9 & 20.1 & 2.0 & 2.0 & -24.9 & -18.0 & -6.9 & $\begin{array}{ll}-20.9 & 7.1 \\
\end{array}$ & 0.334 \\
\hline Anxiety disorder & 8.2 & 4.7 & 1.7 & 1.9 & -6.5 & -2.8 & -3.7 & $-10.9 \quad 3.5$ & 0.313 \\
\hline Psychosis/developmental disorder & 6.0 & 1.2 & 1.2 & 1.8 & -4.8 & 0.6 & -5.4 & $-12.2 \quad 1.4$ & 0.121 \\
\hline Other & 12.5 & 4.6 & 2.9 & 3.5 & -9.6 & -1.1 & -8.5 & $-17.0 \quad 0.1$ & 0.053 \\
\hline \multicolumn{10}{|l|}{ Comorbid mental disorders } \\
\hline 2 or more & 0.9 & 1.7 & 0.1 & 0.2 & -0.8 & -1.5 & 0.7 & $-18.7 \quad 3.3$ & 0.592 \\
\hline \multicolumn{10}{|l|}{ Antidepressant prescription } \\
\hline Any antidepressant & 28.2 & 25.8 & 10.9 & 10.8 & -17.3 & -15.0 & -2.3 & -13.18 .5 & 0.680 \\
\hline Potentially inappropriate antidepressant & 0.5 & -0.1 & 1.6 & 1.4 & 1.1 & 1.6 & -0.5 & $-1.8 \quad 0.8$ & 0.463 \\
\hline \multicolumn{10}{|l|}{ Psychiatric service use } \\
\hline Psychotherapy and mental health counseling & 9.1 & 10.9 & 0.4 & 0.4 & -8.7 & -10.4 & 1.8 & -6.610 .1 & 0.679 \\
\hline \multicolumn{10}{|l|}{ Sample size } \\
\hline Unweighted sample & \multicolumn{2}{|c|}{323} & \multicolumn{2}{|c|}{15,273} & - & - & - & \multicolumn{2}{|c|}{15,596} \\
\hline Weighted visits & \multicolumn{2}{|c|}{$1,748,058$} & \multicolumn{2}{|c|}{$91,841,986$} & - & - & - & \multicolumn{2}{|c|}{$93,590,045$} \\
\hline
\end{tabular}

No differential effect was found in terms of overall and potentially inappropriate antidepressant prescribing patterns and provision of nonpharmacological psychiatric services. First, these findings are consistent with previous studies, which show no or uncertain improvement of depressionrelated outcomes due to depression screening. ${ }^{27,28}$ This may be due to a broadly defined guideline in the USPSTF depression screening recommendation statements, which did not specify which depression screening instruments should be used in primary care practices. Other possible reasons include acceptability or credibility issues regarding depression screening among patients and health care providers (e.g., uncertainty with respect to the evidence).

One of the important clinical implications is the quality of current depression screening tools in primary care practice. For example, false-positive rates of existing screening tools are relatively high, ${ }^{29}$ such that primary care physicians do not order follow-up tests for mental health diagnoses other than depression. Alternatively, primary care physicians may not be well informed about procedures when several screening tools are available with little evidence of such tools. ${ }^{29}$ According to the American Geriatrics Society, the Patient Health Questionnaire-2 is recommended as an initial depression screening tool and a 15-item Geriatric Depression Scale as a follow-up test for older adults. ${ }^{30}$ In other words, screening tools are meant as a way to alert primary care physicians to the possible presence of a mental health condition and should be followed by more assessments. However, using nationally representative secondary data, our study is limited to investigating the details of primary care physician practice patterns for utilizing depression screening. Future research is needed to better understand the adherence of primary care physicians to the depression screening guideline and its related outcomes.

A recent study found that depression screening was associated with a decreased rate of potentially inappropriate antidepressant prescriptions in older adults using the same data source. ${ }^{11}$ Based on our findings and their rationale, it seems that depression screening is still useful, as the provision of depression screening was associated with a decreased rate of potentially inappropriate antidepressant prescriptions in visits made by older adults ${ }^{11}$, this phenomenon, however, was not likely due to recent USPSTF guideline implementation. Future research is still needed to characterize causal pathways for depression screening, diagnoses, and treatments of depression and other psychiatric disorders to further guide the utility of depression screening guidelines for health care providers in primary care settings.

\section{Limitations}

Our study has several limitations. First, the 2009 USPSTF depression screening recommendation distinguishes that the screening service use is recommended if and only if staffassisted depression care supports are in place (i.e., grade B 
recommendation). Otherwise, the screening service may be provided depending on individual circumstances (i.e., grade $\mathrm{C}$ recommendation). ${ }^{5}$ Because the NAMCS does not collect information regarding staff-assisted depression care supports, careful interpretations of the study findings are needed. Currently, no publicly available national data allow us to collect such information. In addition, detailed depression screening strategies are not known in the NAMCS. Future research should address such issues (e.g., types and intensity of depression screening) when examining the roles of depression screening on diagnosing and treating depression and other mental health conditions.

Second, due to the nature of the survey design, the NAMCS only captures up to 3 diagnoses in a sampled visit, and diagnoses from any previous visit are not known. In addition, problems with transferring clinical information across different health care providers or sites may have contributed to missing psychiatric diagnoses in the NAMCS data, as documented elsewhere. ${ }^{31}$ Thus, the NAMCS may have underreported the rates of depression screening, mental health diagnosis, and/or treatment. These limitations should be carefully considered when interpreting our findings.

Strengths of the study include the use of a quasi-experimental DID method to evaluate the effect of the 2009 depression screening recommendation at the national level. ${ }^{25}$ This study adds value to existing literature because no population-based observational study was conducted to support previous studies, as they solely used a randomized controlled trial (RCT) approach. ${ }^{28,32,33}$ While RCT studies focus on efficacy of depression screening in ideal settings, population-based observational studies, such as our study, can evaluate the effectiveness of depression screening with greater validity in real-world settings. For this reason, our study can inform clinical implications of practicing depression screening in primary care settings at the national level.

\section{Conclusions}

This study provides evidence that the 2009 USPSTF depression screening recommendation was associated with a decreased rate of diagnosing any mental disorder but had no effect on antidepressant prescribing patterns and provision of nonpharmacological psychiatric services in office-based outpatient visits made by older adults. In 2016, the USPSTF disseminated its updated recommendation, which remains unchanged that a grade B recommendation is given regardless of staff-assisted depression care supports status. ${ }^{34,35}$ Such a recommendation is notably different from the Canadian Task Force on Preventive Health Care, which recently recommended against depression screening in 2013 because of the evidence that no RCT study supports the effectiveness of depression screening on depression outcomes in primary care settings. ${ }^{33}$ Since evidence of efficacy and effectiveness of depression screening remains mixed, additional population-based observational research with rigorous designs is needed in the near future to strengthen and support current USPSTF depression screening recommendation statements in the United States.

\section{Authors}

TAEHO GREG RHEE, PhD, MSW, Section of Geriatrics, Department of Internal Medicine, School of Medicine, Yale University, New Haven, Connecticut; Yale Center for Outcomes Research and Evaluation (CORE), Yale-New Haven Hospital, New Haven, Connecticut; and Department of Pharmaceutical Care and Health Systems, College of Pharmacy, University of Minnesota, Minneapolis. BENJAMIN D. CAPISTRANT, ScD, School of Social Work, Smith College, Northampton, Massachusetts. JON C. SCHOMMER, PhD; RONALD S. HADSALL, PhD; and DONALD L. UDEN, PharmD, Department of Pharmaceutical Care and Health Systems, College of Pharmacy, University of Minnesota, Minneapolis.

AUTHOR CORRESPONDENCE: Greg Rhee, PhD, MSW, School of Medicine, Yale University, 333 Cedar St., P.O. Box \#208025, New Haven, CT 06520. Tel.: 773.398.9564;

E-mail: tgrhee.research@gmail.com; taeho.rhee@yale.edu.

\section{DISCLOSURES}

Funding for this study was provided by the National Institute on Aging of the National Institutes of Health (\#T32AG019134). The authors declare that they do not have any conflicts of interest. Publicly available data were obtained from the National Center for Health Statistics (NCHS) of the Centers for Disease Control and Prevention (CDC). Analyses, interpretation, and conclusions are solely those of the authors and do not necessarily reflect the views of the Division of Health Interview Statistics or NCHS of the CDC

\section{REFERENCES}

1. World Health Organization. Depression: fact sheet. 2017. Available at: http://www.who.int/mediacentre/factsheets/fs369/en/. Accessed June 1, 2018.

2. Wiese BS. Geriatric depression: the use of antidepressants in the elderly. Br Columbia Med J. 2011;53(7):341-47.

3. Palmer SC, Coyne JC. Screening for depression in medical care: pitfalls, alternatives, and revised priorities. J Psychosom Res. 2003;54(4):279-87.

4. U.S. Preventive Services Task Force. Screening for depression: recommendations and rationale. Ann Intern Med. 2002;136(10):760-64.

5. U.S. Preventive Services Task Force. Screening for depression in adults: U.S. preventive services task force recommendation statement. Ann Intern Med. 2009;151(11):784-92

6. U.S. Preventive Services Task Force. Depression in adults: screening. 2015. Available at: http://www.uspreventiveservicestaskforce.org/Page/ Document/UpdateSummaryDraft/depression-in-adults-screeningl?ds= $1 \&$ s=depression. Accessed June 2, 2018

7. Mojtabai R. Does depression screening have an effect on the diagnosis and treatment of mood disorders in general medical settings?: an instrumental variable analysis of the National Ambulatory Medical Care Survey. Med Care Res Rev. 2011;68(4):462-89. 
8. Rhee TG, Schommer JC, Capistrant BD, Hadsall RL, Uden DL. Potentially inappropriate antidepressant prescriptions among older adults in officebased outpatient settings: national trends from 2002 to 2012. Adm Policy Ment Health. 2018;45(2):224-35.

9. Block LD, Jarlenski MP, Wu AW, Bennett WL. Mammography use among women ages 40-49 after the 2009 U.S. Preventive Services Task Force recommendation. J Gen Intern Med. 2013;28(11):1447-53.

10. Filice CE, Green JC, Rosenthal MS, Ross JS. Pediatric screening urinalysis: a difference-in-differences analysis of how a 2007 change in guidelines impacted use. BMC Pediatr. 2014;14:260.

11. Rhee TG, Capistrant BD, Schommer JC, Hadsall RS, Uden DL. Effects of depression screening on diagnosing and treating mood disorders among older adults in office-based primary care outpatient settings: an instrumental variable analysis. Prev Med. 2017;100:101-11.

12. National Center for Health Statistics. About the ambulatory health care surveys. 2017. Available at: http://www.cdc.gov/nchs/ahcd/about_ahcd.htm. Accessed June 2, 2018.

13. National Center for Health Statistics. Ambulatory health care data: questionnaires, datasets, and related documentation. 2017. Available at: http:// www.cdc.gov/nchs/ahcd/ahcd_questionnaires.htm. Accessed June 2, 2018

14. Olfson M, Blanco C, Wang S, Laje G, Correll CU. National trends in the mental health care of children, adolescents, and adults by office-based physicians. JAMA Psychiatry. 2014;71(1):81-90.

15. American Society of Health-System Pharmacists. American Hospital Formulary Service (AHFS) Drug Information. Bethesda, MD: American Society of Health-System Pharmacists; 2015.

16. Wolters Kluwer. Clinical drug information. Facts and comparisons. 2015. Available at: http://www.wolterskluwercdi.com/. Accessed June 2, 2018.

17. Maust DT, Oslin DW, Marcus SC. Effect of age on the profile of psychotropic users: results from the 2010 National Ambulatory Medical Care Survey. J Am Geriatr Soc. 2014;62(2):358-64.

18. Olfson M, Marcus SC. National patterns in antidepressant medication treatment. Arch Gen Psychiatry. 2009;66(8):848-56.

19. American Geriatrics Society Beers Criteria Update Expert Panel. American Geriatrics Society updated Beers Criteria for potentially inappropriate medication use in older adults. J Am Geriatr Soc. 2012;60(4):616-31.

20. American Geriatrics Society Beers Criteria Update Expert Panel. American Geriatrics Society 2015 updated Beers Criteria for potentially inappropriate medication use in older adults. J Am Geriatr Soc. 2015;63(11):2227-46.
21. National Center for Health Statistics. 2012 NAMCS micro-data file documentation. Available at: ftp://ftp.cdc.gov/pub/Health_Statistics/NCHS/ Dataset_Documentation/NAMCS/doc2012.pdf. Accessed June 7, 2018.

22. Rhee TG, Choi YC, Ouellet GM, Ross JS. National prescribing trends for high-risk anticholinergic medications in older adults. J Am Geriatr Soc. March 26, 2018 [E-pub ahead of print].

23. Rhee TG. Continuing versus new antidepressant use in older adults: U.S. prescribing trends from 2006 to 2015. Eur Geriatr Med. In press.

24. Rhee TG, Mohamed S, Rosenheck RA. Antipsychotic prescriptions among adults with major depressive disorder in office-based outpatient settings: national trends from 2006 to 2015. J Clin Psychiatry. 2018;79(2):17m11970

25. Mander A, Clayton D. HOTDECK: Stata Module to Impute Missing Values Using the Hotdeck Method. Boston College Department of Economics. 2007.

26. Khandker SR, Koolwal GB, Samad HA. Handbook on Impact Evaluation: Quantitative Methods and Practices. Washington, DC: World Bank; 2010.

27. Thombs BD, Ziegelstein RC. Does depression screening improve depression outcomes in primary care? BMJ. 2014;348:g1253.

28. Thombs BD, Ziegelstein RC, Roseman M, Kloda LA, Ioannidis JP. There are no randomized controlled trials that support the United States Preventive Services Task Force Guideline on screening for depression in primary care: a systematic review. BMC Med. 2014;12:13.

29. Bland RC, Streiner DL. Why screening for depression in primary care is impractical. CMAJ. 2013;185(9):753-54.

30. Maurer DM. Screening for depression. Am Fam Physician. 2012;85(2):139-44.

31. Mojtabai R, Olfson M. Proportion of antidepressants prescribed without a psychiatric diagnosis is growing. Health Aff (Millwood). 2011;30(8):1434-42.

32. O'Connor EA, Whitlock EP, Beil TL, Gaynes BN. Screening for depression in adult patients in primary care settings: a systematic evidence review. Ann Intern Med. 2009;151(11):793-803.

33. Thombs BD, Ziegelstein RC. Depression screening in primary care: why the Canadian task force on preventive health care did the right thing. Can J Psychiatry. 2013;58(12):692-96.

34. Siu AL, US Preventive Services Task Force (USPSTF), Bibbins-Domingo $\mathrm{K}$, et al. Screening for depression in adults: US Preventive Services Task Force recommendation statement. JAMA. 2016;315(4):380-87.

35. U.S. Preventive Services Task Force. Final recommendation statement: depression in adults—screening. 2016. Available at: https://www.uspreventiveservicestaskforce.org/Page/Document/RecommendationStatementFinal/ depression-in-adults-screeningl. Accessed June 2, 2018. 